\title{
LVI. Researches upon the products of the decomposition of cyanogen in water
}

\section{Pelouze \& Richardson}

To cite this article: MM. Pelouze \& Richardson (1838) LVI. Researches upon the products of the decomposition of cyanogen in water , Philosophical Magazine Series 3, 12:75, 339-341, DOI: $10.1080 / 14786443808649461$

To link to this article: http://dx.doi.org/10.1080/14786443808649461

册 Published online: 01 Jun 2009.

Submit your article to this journal $[\pi$

Џll Article views: 3

Q View related articles $₫$ 
mixed with the particles of charcoal by which its surface had been blackened.

Concentrated and boiling sulphuric acid chars and decomposes it. In boiling nitric acid it undergoes no apparent change.

According to Sir David Brewster it polarizes light in patches.

Of an uncoloured portion selected for analysis from the centre of the mass, $5 \cdot 14$ grs. gave 15.97 of carbonic acid, and 6.765 of water. These quantities are equal to

\begin{tabular}{|c|c|c|c|}
\hline \multirow{3}{*}{$\begin{array}{l}1 \text { atom of carbon } \\
1 \text { atom of hydrogen }\end{array}$} & \multicolumn{2}{|r|}{ Experiment. } & Theory. \\
\hline & $=76.437$ & $=85 \cdot 910$ & $85 \cdot 965$ \\
\hline & $=12 \cdot 4.79$ & $=14.624$ & $14 \cdot 035$ \\
\hline & & 100.534 & $100^{\circ}$ \\
\hline
\end{tabular}

The excess of hydrogen is to be attributed to the unusual quantity of moisture left in the oxide of copper, which the volatility of the substance prevented me from heating sufficiently high to permit the water to be wholly driven out.

This substance therefore belongs to the group of which olefiant gas is the best known type, and it differs from paraffine chiefly in its tendency to crystallize, and to decompose and blacken by long exposure to the air, or by the action of concentrated sulphuric acid. In the last two properties it agrees with the Middletonite described in the preceding Number of this Journal, p. 261.

Durham, March 1838.

LVI. Researches upon the Products of the Decomposition of Cyanogen in Water*. By MM. Pelouze and Richardoson. $†$

CHEMISTS have possessed up to the present time but very incomplete notions respecting the alteration which an aqueous solution of cyanogen undergoes when exposed simply to the action of light.

M. Vauquelin, who was occupied with this subject in 1818, found that besides ammonia, and a peculiar black matter, there was formed, by the action of cyanogen upon the elements of the water, three distinct acids, viz. carbonic acid,

* This note is the first part of an examination which we have undertaken upon the alteration which several azotized bodies underco by the action of water, heat, \&c., and upon the state of the azote in charcoals of animal origin.

+ Communicated by Mr. Richardson. 
prussic acid, and a new acid which he considered as composed of cyanogen and oxygen.

The opinion of M. Vauquelin upon the nature of this latter substance was solely founded upon theoretical views, for he had neither isolated his new acid, nor studied any of its combinations.

The experiments which we proceed to detail, authorise us to say, that M. Vauquelin had deceived himself in announcing the formation of cyanic acid by the decomposition of cyanogen in water, and that the matter which he had considered as cyanate of ammonia was a mixture of urea and oxalate of ammonia.

A solution of cyanogen in water, prepared in the ordinary manner, was exposed to the action of light, till all odour of cyanogen had disappeared. The new liquid had a strong smell of prussic acid; its colour was slightly yellow, and its reaction neutral. A black, flocky, light substance had fallen to the inferior part of the solution. It was collected upon a filter, and freed from all foreign soluble matters by washing with distilled water. After this purification it was slightly soluble in water and alcohol, insoluble in æther ; soluble, on the contrary, in acetic acid and the caustic alkalies, and possessed the property of forming true salts with the various bases.

The small quantity at our disposal did not permit us to submit it to an examination as rigorous and extended as we could have desired. However, from the analysis of its combination with the oxide of silver we have reason to believe that its true composition may be expressed by the following formula :

$$
\mathrm{N}_{8} \mathrm{C}_{8} \mathrm{H}_{8} \mathrm{O}_{4}
$$

A part of the liquid was boiled, and the vapour disengaged was conducted through lime-water. An abundant precipitate of carbonate of lime was formed, leaving no doubt that carbonic acid was formed during the decomposition of the cyanogen in water. The remainder of the liquid disengaged during its concentration a quantity of ammonia and prussic acid.

The dry residue had a slight yellow colour, and a saline, sharp taste. Treated with alcohol, it was divided into two nearly equal parts. The portion soluble in the alcohol possessed all the characters of urea.

The residue, insoluble in alcohol, was oxalate of ammonia. From the analysis of these two substances and the minute examination of their properties, there can be no doubt respecting their production in the spontaneous decomposition of cyanogen dissolved in water. If $\mathbf{M}$. Vauquelin had pursued the examination which he had commenced of the pro- 
ducts of this decomposition, he would, perhaps, have been the first to make the beautiful discovery, which fifteen years afterwards was made by M. Wöhler in the artificial production of an animal matter; but the small quantity of matter upon which he operated, did not permit him to analyse completely a subject to which he never afterwards returned.

It is exceedingly curious to see a substance of such a simple composition as cyanogen, a substance which is placed by its characters in the system of chemistry, not at the side, but in the very middle of the elements, giving birth, in reacting upon water, to so many different products.

In admitting for the black matter the formula $\mathrm{N}_{8} \mathrm{C}_{8} \mathrm{H}_{8} \mathrm{O}_{4}$, we can explain the decomposition of cyanogen in water by the following equation:

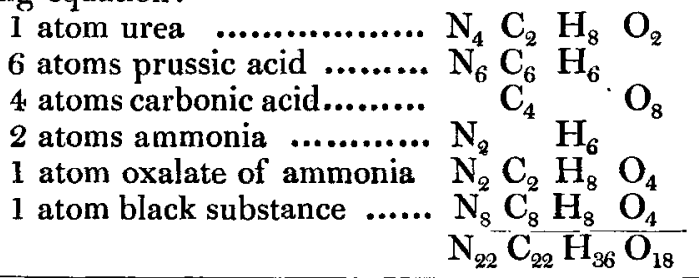

LVII. Notes to Analytical Development, \&c. By J. J. SvLvester, of St. John's College Cambridge, Professor of Natural Philosophy in University College, London.*

\section{Note 1.}

T $\mathrm{N}$ the paper above adverted to, I showed that the meridian plane, i. e. the plane containing the ray and normal, always passed through a line of vibration in the corresponding point. Now the line of force called into action by a displacement in the line of vibration clearly lies in this very plane; for the resolved part of it lies in the line of vibration itself.

Harmony and analogy concurred in making me suspect that as two of these four lines are perpendicular to each other, so are also the other two, or in other words, that the ray is always perpendicular to the direction of unresolved force.

The following investigation verifies this conjecture.

Let $x, y, z$ be the coordinates of a point taken at distance unity from the origin and in any line of vibration; then the cosines of the angles made by the line of force with the axes are as $a^{2} x: b^{2} y: c^{2} z$ respectively.

Let $a$ be the inclination between the line of vibration and the line of force, then

- Communicated by the Author: see vol. xi. p. 461 et scq. and present volume, p. 73 et seq. 